\title{
ethic@ (2) \\ ALÉM DO DIREITO DA LIBERDADE: UMA ANÁLISE REPUBLICANA DA TEORIA DEMOCRÁTICA CRÍTICA DE A. HONNETH
}

\author{
BEYOND FREEDOM'S RIGHT: A REPUBLICAN ANALYSIS \\ OF THE CRITICAL DEMOCRATIC THEORY OF A. HONNETH
}

\author{
NICOLÁS EMANUEL OLIVARES ${ }^{1}$ \\ (UNIVERSITAT DE GIRONA/ESPANHA)
}

\begin{abstract}
RESUMO
No início da década de 2010, A. Honneth delineou uma concepção democrática crítica específica, baseada em um modelo social de liberdade individual, que ele considera superior aos modelos negativos e reflexivos. Honneth considera que a democracia deliberativa depende normativamente e empiricamente do modelo social de liberdade individual, de modo que, se certas condições sociais não são cumpridas, os cidadãos carecem das condições que lhes permitiriam a participação na construção da vontade democrática. Neste trabalho, procederemos à reconstrução dos principais postulados normativos da concepção democrática crítica de Honneth, que define positivamente a justiça como reconhecimento mútuo, contrastando-os especularmente com os da concepção republicana defendida pelo filósofo $P$. Pettit, que se baseia em um modelo negativo de liberdade política entendida como não-dominação. Em resumo, explicaremos quatro atrações comparativas que a teoria de $\mathrm{P}$. Pettit oferece em relação a Honneth em matéria da metodologia, conceito da justiça, classificação de modelos da liberdade, e prioridade da justiça.
\end{abstract}

Palavras-chave: Liberdade política; Modelo social; Democracia; Republicanismo; Não-dominação.

\begin{abstract}
At the beginning of the 2010's, German philosopher A. Honneth outlined a specific critical democratic conception based on a social model of individual freedom, which he considers superior to negative and reflective models. Honneth believes that deliberative democracy depends conceptually and empirically on the social model of individual freedom, so that if certain social conditions are not met, citizens lack the conditions that would allow them to participate in the construction of democratic will. In this work, we will proceed to the reconstruction of the main normative postulates of the critical democratic conception of Honneth, who positively defines justice as mutual recognition, contrasting them specularly with those of the republican conception defended by the Irish philosopher P. Pettit, which is based on a negative model of political freedom understood as nondomination. In summary, we will explain four comparative attractions that $P$. Pettit's theory offers over that of Honneth in terms of methodology, concept of justice, classification of models of freedom, and priority of justice.
\end{abstract}


Keywords: Political liberty; Social model; Democracy; Republicanism; Nondomination.

\section{Introdução}

No início da década de 2010, Honneth ressignificou sua teoria política, publicando sua obra $O$ direito da liberdade (El derecho de la libertad, Katz, 2014). Nesse trabalho sugestivo, propõe-se a defender uma concepção democrática que assume os seguintes pressupostos: a) o uso da reconstrução normativa como ferramenta metodológica; b) a definição de justiça como reconhecimento mútuo; c) uma classificação sui generis dos modelos de liberdade individuais (negativos, reflexivos e sociais); e d) a primazia temporal e normativa da noção de ordem social justa sobre a de legitimidade democrática.

Nosso objetivo geral, neste trabalho, consistirá em defender as vantagens comparativas da concepção republicana defendida por P. Pettit, que: a) utiliza o equilíbrio reflexivo como ferramenta metodológica para a reconstrução normativa; b) define justiça como não-dominação; c) usa uma classificação padrão de modelos de liberdade política; e d) concede a primazia temporal e normativa da noção de justiça política sobre a noção de justiça social.

Com esse objetivo em mente, na seção I - Uma teoria democrática crítica reconstruiremos os pressupostos conceituais e normativos do modelo democrático de Honneth; então na seção II - Uma teoria republicana cívica apresentaremos as bases do modelo republicano de $P$. Pettit. Em ambos os casos atenderemos aos seguintes quatro aspectos: metodologia empregada, conceito da justiça, classificação de modelos da liberdade, e prioridade da justiça. A seguir, faremos quatro objeções ao modelo de Honneth. Finalmente, na seção final, delinearemos quatro argumentos correlativos sobre a maior atratividade comparativa do modelo de P. Pettit sobre o de Honneth.

\section{Uma teoria democrática crítica}

Nesta seção, procederemos à reconstrução das quatro principais suposições normativas do modelo democrático de Honneth.

\section{1 - Reconstrução normativa como ferramenta metodológica}

Primeiro, com relação ao aspecto metodológico, Honneth, seguindo à sua maneira uma linha hegeliana, pretende usar a reconstrução normativa 
como ferramenta metodológica. Isso requer levar em consideração os valores, princípios e ideais já existentes em uma dada sociedade, ou seja, imanentes a ela, estando atento à sua história política, econômica e social, analisando se suas normas, instituições e medidas concretas satisfazem o referido quadro normativo de referência particular, que ele denomina eticidade democrática (HONNETH, 2014, p. 19). A proposta de Honneth parte da premissa de que, em certos contextos próprios da filosofia prática, são os hábitos praticados intersubjetivamente, e não apenas as convicções cognitivas, que compõem o escopo da eticidade pública. Dessa forma, a reconstrução normativa tem não apenas uma face descritiva, mas também uma face crítica, no sentido de objeção às práticas existentes ou esboço preliminar de caminhos de desenvolvimento ainda não esgotados (HONNETH, 2014, p. 21-23).

Nesse contexto, Honneth contrasta as perspectivas metodológicas kantianas e hegelianas. Por um lado, Kant sustentou dedutivamente que "os princípios normativos pelos quais a legitimidade moral da ordem social deveria ser medida não podiam ser desenvolvidos a partir da estrutura institucional existente, mas tinham que ser executados independentemente dela" (HONNETH, 2014, p. 11). ${ }^{2}$ Por outro lado, Hegel pretendia reconstruir, de maneira normativa indutiva, a partir das circunstâncias sociais particulares de cada época, aquelas instituições consideradas racionais, pois garantiam a liberdade individual (HONNETH, 2014, p. 13). Desse modo, Hegel pretendia "apresentar a realidade institucional de seu tempo como racional já em suas características decisivas e, inversamente, demonstrar que a razão moral já é realizada nas instituições nucleares modernas" (HONNETH, 2014, p. 15).

No quadro desse debate, Honneth considera que, na teoria de Kant, "os princípios da justiça são baseados antecipadamente em um primeiro nível, sem considerar a facticidade das condições sociais" (HONNETH, 2014, p. 91), de modo que "parece sensato retomar a intenção hegeliana de delinear uma teoria da justiça baseada nos requisitos muito estruturais das sociedades de hoje" (HONNETH, 2014, p. 16). Em outras palavras, Honneth considera que "os padrões de justiça só podem ser analisados usando ideais de fato institucionalizados em cada sociedade" (HONNETH, 2014, p. 18).

Assim, Honneth afirma que

a reconstrução normativa toma diretamente os valores imanentemente justificados como um guia para a elaboração e classificação do material empírico: as instituições e práticas são analisadas e apresentadas com base em seu desempenho normativo na ordem de importância que têm para a 
encarnação e realização social dos valores legitimados pela sociedade (HONNETH, 2014, p. 19).

Conforme avançamos, Honneth se propõe a identificar as condições axiológicas estruturais ou imanentes das sociedades contemporâneas, o que lhe permite moldar uma plataforma normativa específica para cada sociedade democrática, que ele chamará de eticidade. No entanto, deve-se notar que o procedimento de reconstrução normativo constitui não apenas uma ferramenta para identificar instâncias existentes de eticidade, mas também uma avaliação crítica delas, à luz dos valores inerentes a cada sociedade (HONNETH, 2014, p. 21-23). Não obstante, como as críticas são dadas sob essa perspectiva metodológica? A resposta de Honneth é que esses mesmos padrões "pelos quais se distinguiram [aquelas instituições e práticas] do caos da realidade são usados para censurá-las por uma incorporação insuficiente, ainda incompleta, dos valores geralmente aceitos" (HONNETH, 2014, p. 23).

Apesar disso, a partir dessa perspectiva metodológica reconstrutiva Honneth adverte que a relação entre o objetivo ético e os princípios da justiça não é predeterminada, mas requer "um esclarecimento racional não apenas da extensão, mas também da forma de exercício dessa liberdade individual que deve servir plenamente como um guia geral" (HONNETH, 2014, p. 34). Com isso, considera que o fundamento de uma certa concepção de justiça requer anteriormente "uma diferenciação entre diferentes modelos de liberdade individual", o que "permitiria descartar aqueles que não são atraentes e fornecer argumentos em defesa daquele que parece adequado" (HONNETH, 2014, p. 34). A diferenciação desses três modelos será analisada em uma seção posterior. Antes disso, é necessário explicitar a concepção de justiça e a complementaridade das preferências políticas assumidas por Honneth.

\section{I.2 - Justiça entendida como reconhecimento mútuo}

Segundo, Honneth define justiça como reconhecimento mútuo. O referido padrão intersubjetivo refere-se à

[...] experiência recíproca de $[\ldots]$ que ambos os sujeitos reconhecem a necessidade da complementaridade de seus respectivos objetivos, isto é, que eles veem em sua contraparte o outro de si mesmos, [assim,] a liberdade, até então apenas reflexiva, é estendida para se tornar intersubjetiva (HONNETH, 2014, p. 67-68). 
A noção de reconhecimento mútuo constitui a base ética crítica sobre a qual Honneth constrói seu modelo social de liberdade individual, uma vez que, em sua opinião, o desejo de liberdade de cada indivíduo só pode ser realizado dentro ou com a ajuda de certas instituições. Dessa forma, o modelo social de liberdade parte da tese de que o indivíduo é livre, se, e somente se, "no âmbito das práticas institucionais, ele se encontra com uma contraparte à qual está conectado por uma relação de reconhecimento mútuo, porque pode ver nos objetivos daquela uma condição da realização dos seus próprios objetivos" (HONNETH, 2014, p. 68). Como pode ser visto, existe uma conexão íntima entre os conceitos de liberdade social individual e reconhecimento mútuo, pois "para que a liberdade individual se manifeste na realidade objetiva [...] o sujeito deve querer realizar objetivos cuja realização supõe a existência de outros sujeitos que têm objetivos complementares" (HONNETH, 2014, p. 72).

Nesse arcabouço teórico, Honneth, em crítica aberta às concepções neokantianas, aponta que, atualmente, na questão da Teoria da Justiça o objetivo normativo não é mais a eliminação da desigualdade, mas a prevenção e erradicação do desprezo, de modo que "as categorias centrais dessa nova divisão não são mais distribuição equitativa ou igualdade de bens, mas dignidade e respeito" (HONNETH, 2010, p. 10). Assim, enquanto o conceito de distribuição equitativa está ligado a uma concepção de justiça que visa criar igualdade social por meio da redistribuição de bens que garantem a liberdade individual, o segundo conceito define quais devem ser as condições para uma sociedade justa, orientada para o reconhecimento da dignidade ou integridade individual de todos os seus membros (HONNETH, 2010, p. 10).

A esse respeito, Honneth ressalta que existem duas linhas argumentativas em torno dessa mudança no paradigma regulatório. Por um lado, o movimento do conceito de redistribuição para o de reconhecimento seria devido a um enorme desencanto político da cidadania democrática ocidental contemporânea ao ver o repetido fracasso de seus representantes em questões de igualdade social. Por outro lado, esse fenômeno seria justificado em termos de um aumento valioso da sensibilidade moral dos cidadãos ocidentais, entendendo que no reconhecimento intersubjetivo está implicado o elemento essencial do seu conceito post-metafísico de justiça (HONNETH, 2010, p. 11-12).

Da mesma forma, Honneth destaca que o conceito de reconhecimento mútuo pode ser definido de maneira negativa, com base na ausência de desprezo sofrido por um indivíduo em um dos principais campos morais, enquanto o conteúdo moral desse termo pode ser definido positivamente por uma eticidade democrática deliberativa que implica a interação ativa 
das pessoas afetadas em uma discussão pública contínua (HONNETH, 2010, p. 26-44). Por esse motivo, Honneth adverte que o conceito de justiça social de inspiração kantiana, limitado a certos aspectos da redistribuição na esfera política, deve ser modificado. Em outras palavras, o conceito honnethiano de moralidade post-metafísica ou eticidade democrática implicaria uma extensão do conceito kantiano de moralidade social, uma vez que o objetivo normativo do reconhecimento mútuo "não pode ser totalmente resumido no conceito de justiça, mas deve ser reconstruído no quadro de uma concepção formal de vida satisfatória" (HONNETH, 2010, p. 31). Da mesma forma, uma concepção relacional, social e intersubjetiva de autorrealização pessoal é explícita em sua definição do conceito de reconhecimento mútuo, uma vez que "depende de pressupostos que não estão disponíveis gratuitamente para o indivíduo, porque este último só pode alcançá-los com a ajuda de seus parceiros de interação" (HONNETH, 2010, p. 32). ${ }^{3}$

Em resumo, Honneth considera que sua concepção ética crítica da democracia deliberativa depende normativamente e empiricamente do modelo social de liberdade individual mencionado anteriormente, apontando que, se certas condições exigidas pela liberdade social não são minimamente cumpridas, "carecem aos cidadãos as condições sociais que Ihes permitiriam uma participação ilimitada e não coercitiva na construção da vontade democrática" (HONNETH, 2014, p. 340). Nesse sentido, conforme avançamos, na próxima seção, vamos nos referir à classificação sui generis de modelos de liberdade individual de Honneth, que visa a justificar a superioridade normativa do chamado modelo social sobre seus rivais negativos e reflexivos.

\section{I.3 - Uma classificação sui generis de modelos de liberdade individual}

Terceiro, Honneth ressalta que devemos distinguir três modelos normativos de liberdade individual, a saber, negativo, reflexivo e social.

Em primeiro lugar, coloca o nascimento do modelo negativo de liberdade individual na época das guerras civis religiosas dos séculos XVI e XVII. Nesse contexto, T. Hobbes afirma que a autodeterminação individual é apenas negativa, pois "a liberdade humana [...] nada mais é do que a ausência de resistências externas que podem impedir o movimento dos corpos naturais" (HONNETH, 2014, p. 37). Por sua vez, R. Nozick constrói sua concepção negativa de liberdade individual com base na noção de um sujeito político típico da segunda metade do século XX. Em sua opinião, "ser livre significa ser capaz de atingir tantos objetivos de vida egocêntricos, 
totalmente caprichosa, quanto sejam compatíveis com a liberdade de todos os outros cidadãos" (HONNETH, 2014, p. 41).

Honneth objeta que, em uma ordem jurídica libertária, como a proposta por T. Hobbes ou R. Nozick, os sujeitos não têm a oportunidade de avaliar sua conformidade com as medidas estatais, não são considerados autores e avaliadores de princípios legais, dado que eles não estão incluídos nos procedimentos para criá-los e revê-los, mas apenas "podem medir a legitimidade da ordem estatal individualmente com o padrão de seus próprios interesses" (HONNETH, 2014, p. 44). Em outros termos, o modelo negativo de liberdade individual protege os interesses individuais e não inclui a ideia de interesse comum, ou seja, "um interesse em cooperação com todos os outros" (HONNETH, 2014, p. 45). Honneth adverte que esse modelo negativo de liberdade individual "se refere inteiramente à liberação externa da ação, enquanto seus objetivos são deixados ao jogo de forças que operam causalmente" (HONNETH, 2014, p. 45). Portanto, o modelo negativo não inclui, explicitamente em sua definição, a capacidade do indivíduo de identificar e projetar seus próprios objetivos políticos, mas é baseado em um raciocínio causal (HONNETH, 2014, p. 46).

Em segundo lugar, Honneth afirma que os pressupostos do modelo reflexivo de liberdade individual encontram sua origem na teoria republicana aristotélica, que afirma que, para ser livre, o indivíduo deve ser capaz de tomar suas próprias decisões e, dessa maneira, influenciar sua própria vontade (HONNETH, 2014, p. 47). Mais precisamente, a ideia de liberdade individual reflexiva considera "livre aquele indivíduo que consegue se relacionar consigo mesmo de tal maneira que só se deixa guiar em suas ações por suas próprias intenções" (HONNETH, 2014, p. 48). Na versão de J. J. Rousseau "uma ação não pode ser considerada livre apenas porque é executada no mundo exterior sem encontrar resistência, mas apenas quando a intenção de a executar se origina da própria vontade" (HONNETH, 2014 , p. 48). Na versão de I. Kant, "o sujeito humano deve se considerar livre porque [...] ele tem não apenas a capacidade de se dar leis para agir, mas também a capacidade de operar de acordo com elas", atendendo a "um discernimento das razões corretas, isto é, racionais" (HONNETH, 2014, p. $51)$.

Imediatamente depois, Honneth passa a criticar o modelo reflexivo de liberdade individual, defendido por vários autores, incluindo, segundo ele, J. Habermas, observando que a expansão do eu (individual) para o nós (coletivo) sustentada pela noção ética do discurso da autolegislação não cobre totalmente a extensão da liberdade intersubjetiva, uma vez que não inclui "o fato de que o eu e os nós só poderiam executar sua autodeterminação se encontrassem, na realidade social, condições 
institucionais que oferecessem uma oportunidade para atingir seus objetivos" (HONNETH, 2014, p. 55). Honneth argumenta que o modelo reflexivo da liberdade individual não incorpora adequadamente as próprias condições institucionais e sociais que tornariam possível o exercício da liberdade. Segundo esse autor, no modelo reflexivo da liberdade individual, as variáveis empíricas não ideais "são adicionadas do lado de fora, de forma aditiva, como elementos da justiça social, mas não são pensadas como seu momento interno" (HONNETH, 2014, p. 62). Pelo contrário, Honneth afirma que o modelo social da liberdade individual considera que as condições institucionais e sociais não devem ser interpretadas como simples extensões externas, mas como componentes imanentes à ideia de liberdade (HONNETH, 2014, p. 63).

Em terceiro lugar, ao falar de um modelo social de liberdade individual, Honneth aponta, então, que nesse modelo a realidade social não é considerada um simples aditivo, mas um meio e condição para a execução da liberdade, pois afirma que "o sujeito individual pode apenas realizar as conquistas reflexivas da autodeterminação ao interagir em uma entidade social, que reciprocamente realiza o mesmo tipo de conquista" (HONNETH, 2014, p. 64-65). Em suma, define a noção de liberdade social "como resultado de um esforço teórico para ampliar os critérios que servem de base para o pensamento de liberdade reflexiva à esfera que tradicionalmente se opõe ao sujeito como realidade externa" (HONNETH, 2014, p. 66). Em outras palavras, a chave do modelo social da liberdade individual residiria em uma concepção de instituições sociais, segundo a qual "os sujeitos se relacionam de tal maneira que podem conceber sua contraparte como o outro de si mesmos" (HONNETH 2014, p. 67). Assim, "sob a condição de que ambos os sujeitos reconheçam a necessidade de complementaridade de seus respectivos objetivos", produz-se "uma relação de reconhecimento mútuo", porque "este pode ver nos objetivos daquela uma condição da realização de seus próprios objetivos" (HONNETH, 2014, p. 68).

I. 3 - A noção de uma ordem social justa: sua prioridade temporal e normativa sobre a ideia de legitimidade democrática

Quarto, em clara rejeição dos modelos negativos e reflexivos da liberdade individual, Honneth aponta, em O Direito da Liberdade, que

Se, para alcançar a liberdade, a ação é suficiente, seja sem limitação externa ou em uma atitude reflexiva, os sujeitos podem então ser considerados suficientemente livres mesmo antes de qualquer integração em uma ordem social. Se, por 
outro lado, o sujeito verdadeiramente livre é concebido apenas onde seus objetivos são cumpridos ou realizados pela própria realidade, então a relação entre o processo de legitimação e a justiça social deve ser revertida em certa medida: primeiro, é necessário poder pensar aquele sujeito como integrado em estruturas sociais que garantem sua liberdade antes que ele possa ser colocado como um ser livre em processos que garantem a legitimidade da ordem social (HONNETH, 2014, p. 83).

O modelo social de liberdade individual parte da hipótese segundo a qual a construção de uma ordem justa deve ser colocada diante do processo democrático de tomada de decisão realizado por sujeitos isolados ou unidos, ou seja, a prioridade é a existência temporal e normativa de um sistema institucional que garanta o reconhecimento mútuo dos cidadãos em diversas esferas da vida social, bem como a possibilidade de se posicionarem contra a ordem resultante de deliberação e decisão (HONNETH, 2014, p. 85). Em termos da linguagem usada nos debates atuais sobre justiça política, isso significa que, para Honneth, tanto temporal quanto normativamente, "as teorias de uma democracia deliberativa têm como pré-condição necessária circunstâncias justas [...] que não podem ser consideradas como resultado de um processo que elas colocam no centro" (HONNETH, 2014, p. 439).

Nesse contexto teórico específico, Honneth esclarece aqueles que, em sua opinião, constituem requisitos fundamentais para um exercício igualitário de liberdade social na vida pública democrática: 1) a existência de certos direitos individuais, como liberdade de pensamento e expressão, liberdade de associação e participação política, liberdade de protesto e greve, entre outros; 2) a presença de um genuíno espaço público para comunicação, discussão, deliberação e decisão política, que permita a troca de opiniões por diferentes indivíduos e grupos afetados; 3) a operação de um sistema de mídia de massa altamente diferenciado, plural e complexo, mas verdadeiro, bem informado e transparente, que permita identificar, descrever e analisar causas e eventos políticos públicos; 4) a predisposição constante, ativa e genuína de uma parte importante dos cidadãos a participar da construção discursiva da vontade popular, bem como a realizar atividades deliberativas e não deliberativas presenciais e não presenciais que mantêm ativas as disputas de opinião pública; e 5) a existência de uma cultura cívica de promoção do bem comum, facilitando, promovendo e gerando forças coesas de solidariedade, cooperação, compreensão e participação, pois, caso contrário, os interesses particulares de alguns prevalecerão sobre os de outros (HONNETH, 2014, p. 387-391). ${ }^{4}$ 


\section{Uma teoria cívica republicana}

Nesta seção, explicaremos as quatro principais suposições da concepção republicana cívica defendida por Philip Pettit.

\section{1 - A ferramenta metodológica do equilíbrio reflexivo}

Em primeiro lugar, Pettit assume explicitamente que a ferramenta metodológica que ele adota "é a que John Rawls [...] descreveu como equilíbrio reflexivo", isto é, estabelecendo princípios gerais para a regulação de um determinado campo, derivando de certas implicações empíricas para casos específicos, a fim de "ver como essas implicações se encaixam no que consideramos credível na reflexão; e ir e vir na busca de ajustes em qualquer extremo que possa promover coerência geral" (PETTIT, 2012, p. 20).

Pettit destaca que "a metodologia do equilíbrio reflexivo é relevante para a interpretação da liberdade como não-dominação", bem como esse modo de pensar a liberdade política "permite desenvolver teorias de justiça social, legitimidade política e soberania internacional que resistem bem aos testes que sustentariam o equilíbrio reflexivo" (PETTIT, 2012, p. 20).

O objetivo de Pettit é delinear uma teoria da justiça, política e social, levando em consideração as características estruturais das sociedades atuais (PETTIT, 2014, p. xxviii), sem deixar de aspirar a um horizonte normativo emancipatório, onde os cidadãos não sofrem dominação pública ou privada. As premissas necessárias para realizar tal empreendimento teórico baseiam-se em uma leitura crítica da realidade social, que resgata certos valores, instituições e práticas, sem cair no erro de comprometer-se com a reprodução da ordem social atual, muito menos na posição particularista segundo a qual haverá tantos valores, instituições e práticas valiosas quantas forem as sociedades identificadas. Dessa maneira, se o ideal regulador republicano cívico não estiver instalado nos padrões de justiça institucionalizados de fato em uma determinada sociedade, as injustiças existentes poderão ser reproduzidas, mas poderão ser buscados outros cursos de ação política que nos permitam promover a liberdade como não-dominação (PETTIT, 2014, p. 1-20).

Essa reconstrução crítica da realidade social, proposta pelo republicanismo, significará que, do conjunto de valores, práticas e organizações sociais, apenas aqueles que possam ser considerados essenciais para a promoção da liberdade, entendida como não-dominação, serão tomados e apresentados, independentemente de esses valores, 
práticas e organismos sociais serem geralmente aceitos ou não, de modo que a reconstrução crítica implica necessariamente reordená-los sem visar à sua mera reprodução, mas à sua contribuição para um sistema político mais amplo construído em torno desse objetivo emancipatório (PETTIT, 2012, p. 1- 25).

Dessa maneira, na teoria cívica republicana, os princípios da justiça baseiam-se considerando a facticidade das condições sociais atuais, sem tentar encontrar nelas uma moralidade particularista e imanente a reproduzir (PETTIT, 2014, p. 1-20). A teoria cívica republicana não pretende fechar de uma vez por todas a lacuna entre demandas normativas e realidade social, evitando assim certo idealismo normativo e construindo princípios de justiça que se baseiam na conveniência e viabilidade de normas, instituições e medidas políticas que eles projetam (PETTIT, 2014, p. $x i-x x v i i i)$.

\section{II.2 - Justiça entendida como não-dominação}

Em segundo lugar, a concepção republicana cívica de Pettit define o conceito de liberdade política como não-dominação, pois um cidadão tem a possibilidade de viver sem estar sujeito ao poder arbitrário atual ou potencial de um terceiro (PETTIT, 2012, p. 5- 8). A concepção de liberdade política entendida como não-dominação implica que todo cidadão deve "ser capaz de exercer certas liberdades básicas ou fundamentais, como costuma ser chamado, sem ter que responder a nenhum professor ou dominador". Em outras palavras, "a ausência de dominação implica a ausência de sujeição à vontade de outros" (PETTIT, 2014, p. xv). Outra maneira de definir liberdade como não-dominação é apontar a possibilidade efetiva de uma pessoa ter garantias adequadas contra todos os tipos de interferência arbitrária em suas decisões, ou seja, qualquer interferência realizada sem o consentimento ou permissão da vítima (PETTIT, 2014, p. xvi).

Essa concepção do valor da liberdade política é apresentada como um meio termo justo entre dois extremos questionáveis, a concepção liberal negativa e a concepção populista positiva. Por um lado, como a concepção liberal negativa, a concepção republicana entende a liberdade em termos de negação de algo, mas aqui a interferência em si não é negada, mas apenas aquela interferência que se qualifica como arbitrária. Por outro lado, como a concepção populista positiva, a concepção republicana atribui ao conceito de liberdade política certo julgamento avaliativo, o que tornaria possível determinar se uma interferência é arbitrária ou não. Porém, esse julgamento avaliativo não requer necessariamente o desenvolvimento de um comportamento, um estado de espírito, uma predisposição psicológica 
ou um sacrifício moral, mas simplesmente avalia a falta de subordinação de uma pessoa à vontade de outra. Dessa forma, o conceito de liberdade republicana constitui uma relação normativa intersubjetiva expressada em termos de um status legal, que só é alcançado mediante o cumprimento de certas regras institucionais (SILVA, 2011, p. 38-40).

Por sua vez, o republicanismo cívico de $P$. Pettit promove dois critérios políticos centrais, que convergem no objetivo final da não-dominação não política. Por um lado, promove a legitimidade política, entendida como a consistência entre a coerção exercida sobre os cidadãos e sua liberdade entendida como não-dominação. Os cidadãos devem estar em posição de controlar a interferência do Estado em suas vidas, definindo a direção em que ele deve agir. A legitimidade política de se doar impede a dominação pública do Estado sobre os indivíduos. Por outro lado, promove a justiça social, entendida como o empoderamento dos cidadãos no exercício das liberdades básicas, definidas como desdobramentos da ideia mais geral de liberdade como não-dominação. A justiça social da doação requer uma infraestrutura adequada para o desenvolvimento social equitativo e impede a dominação privada entre indivíduos, já que não permite que uns indivíduos interfiram arbitrariamente na vida de outros (PETTIT, 2012, p. 297-301).

No entanto, atualmente, Pettit reformulou os termos, mas não o conteúdo, de sua posição republicana cívica, diferenciando os princípios de justiça política e justiça social, mantendo intacto o segundo mandamento e mudando o primeiro, que passa da legitimidade política à justiça política (PETTIT, 2014; 2015). O conteúdo, como advertimos, permanece inalterado, pois "questões relacionadas à justiça social são aquelas que tratam das relações entre determinados cidadãos e uma determinada sociedade" (PETTIT, 2014, p. xvii); enquanto "questões relacionadas à justiça política são aquelas relacionadas às relações entre certos cidadãos e o governo que regula suas vidas" (PETTIT, 2014, p. xix-xx).

Dessa forma, Pettit propõe como ideal regulador republicano entender a liberdade política como não-dominação, que delineia como um horizonte normativo a plena reciprocidade entre os cidadãos e o Estado, mas não a exige como pré-condição para a deliberação democrática. Em outros termos, os processos de deliberação e decisão política, realizados por representados ou representantes, não pressupõem a existência de uma ordem social justa já estabelecida, muito menos exigem que sujeitos políticos individuais e coletivos complementem plenamente seus interesses, preferências e opiniões, mas abre espaço para a diversidade. Isso é totalmente condizente com o que J. Waldron chamou de circunstâncias da política, isto é, a existência de discordâncias profundas, persistentes e 
inerradicáveis, não apenas em relação ao bem, mas também ao correto (WALDRON, 2005, p. 1-10). Nas palavras de Pettit, "é comum, na filosofia política contemporânea, que em quase todas as sociedades seja provável que existam muitas visões diferentes do que a justiça social exige" (PETTIT, 2015, p. 13-14). Dessa maneira, o republicanismo cívico admite desacordo em questões de justiça e legitimidade como um ponto de partida agonístico buscando orientar o comportamento humano de acordo com um ideal moral não particularista, não perfeccionista e abrangente, como o da nãodominação (PETTIT, 2012; 2014; 2015).

\section{II.3 - Uma classificação padrão de modelos de liberdade}

Terceiro, o republicanismo cívico de $\mathrm{P}$. Pettit conecta-se às ideias principais da tradição histórica do pensamento republicano, e as distingue das ideias liberais e comunitárias (PETTIT, 2012, p. 4).

Em primeiro lugar, as discussões existentes entre: a) liberais, sejam eles compreendidos como liberais igualitários ou libertários; b) comunitários, independentemente de poderem ser definidos como republicanos abrangentes ou populistas radicais etc. Republicanos, no entanto, geralmente são classificados como clássicos ou contemporâneos, perfeccionistas ou consequencialistas, representativos ou participativos, nos termos da bibliografia mais respeitada, analisada e discutida sobre filosofia política contemporânea (KYMLICKA, 2002). Não é assim que acontece, porém, com a distinção entre modelos negativos, reflexivos e sociais feitos por Honneth, que parece ser uma classificação forçada, que não é suficientemente sensível à complexidade, variedade e especificidade das concepções filosóficas políticas mencionadas.

Já Pettit traça conexões de significado entre sua concepção republicana e certas versões das teorias liberais e comunitárias. Quanto ao liberalismo, ele ressalta que "embora exista uma profunda diferença entre os ideais orientadores das abordagens, o conflito entre republicanismo e liberalismo não deve ser exagerado" (PETTIT, 2012, p. 11), uma vez que quase todas as formas de liberalismo apoiaram certos pilares republicanos, como as noções de constituição mista e cidadania da oposição. Nesse sentido, os ideais liberais do Estado de Direito, a separação de poderes e liberdade de expressão poderiam ser considerados reflexos desses ideais institucionais republicanos. Em relação ao comunitarismo, ele afirma que compartilha, com o republicanismo cívico, a ideia de que a liberdade política constitui um status que ninguém pode gozar "fora de uma comunidade em que os cidadãos são poderosos e vigilantes o suficiente para monitorar e impor controles ao governo", para que a liberdade política individual seja 
sustentada "com base nesse compromisso político de grupo" (PETTIT, 2012, p. 17).

Assim, como pode ser visto, a classificação oferecida por Pettit (2014) é notoriamente mais precisa, atraente e construtiva do que a oferecida por Honneth (2014). Em primeiro lugar, é mais preciso atentar para as categorias, rótulos e usos semânticos atribuídos pelos próprios autores às suas próprias teorias políticas, evitando a subinclusão ou superinclusão em uma categoria de grande diversidade de teorias filosóficas políticas. Nesse sentido, Pettit distingue entre ética liberal igualitária, libertária, ética discursiva, ética crítica, teorias comunitária e republicana (PETTIT, 2012, p. 1-25). Em segundo lugar, é mais pertinente, pois permite descrever e criticar essas teorias da liberdade política usando seus próprios termos, hipóteses e teses, sem recorrer a conexões fracas de significado ou a reconstruções maniqueístas, além de demonstrar que o republicanismo cívico tem sua própria linguagem, que não é completamente estranha à de outras teorias. Nesse sentido, Pettit busca constantemente identificar, nas teorias filosóficas políticas rivais, elementos, teses ou hipóteses as quais concordariam com sua própria proposta republicana cívica, o que torna esse esforço de conexão, analogia e tradução conceitual uma excelente estratégia de apresentação de suas ideias (PETTIT, 2015, p. 9-12). Terceiro, a classificação usada por Pettit é sensível às várias condições normativas não ideais em vigor, uma vez que é oferecida como uma bússola moral para a resolução dos complexos problemas morais, políticos e sociais de hoje. Com isso, a teoria cívica republicana de Pettit tem reivindicações de cidadania menos exigentes que a de Honneth, mas ao mesmo tempo possui uma capacidade transformadora maior da realidade social, preocupando-se em persuadir a conveniência e a viabilidade de sua teoria, não apenas para outras e outros filósofos políticos, mas principalmente para cidadãos e representantes reais (PETTIT, 2014, p. xi-xxviii).

\section{4 - A prioridade temporal e normativa da justiça política sobre a justiça social}

Quarto, Pettit apontou que "um fracasso na legitimidade política comprometeria mais profundamente a solidez da liberdade que um fracasso apenas na justiça social", dado que a falta de justiça social nos tornaria vulneráveis apenas diante de nossos concidadãos, enquanto a falta de legitimidade política nos tornaria vulneráveis diante deles e do Estado. Em outras palavras, Pettit adverte que, se estivermos sujeitos à dominação de um governo, não teremos influência política e controle sobre a direção dos principais assuntos do governo, assim como seremos vítimas dos abusos desses concidadãos que, porventura, tiram proveito da ausência de um 
governo legítimo. Sendo assim, é evidente que "o domínio público tem custos mais profundos do que os do domínio privado" (PETTIT, 2012, p. 2425).

Assim, Pettit afirma que o ideal republicano de liberdade como nãodominação dá prioridade à legitimidade e ao controle democráticos. Quaisquer que sejam as políticas que o governo apoie, nenhuma deve ser implementada, a menos que seja adotada sob uma forma de supervisão cidadã da qual todos participemos igualmente. Essa é a única garantia contra o efeito duplamente incapacitante do domínio público (PETTIT, 2012, p. 25).

Nesse sentido, Pettit alerta que um número significativo de especialistas em filosofia política contemporânea reduz a ideia de justiça à noção de justiça social. Enquanto que, de sua perspectiva republicana cívica, ao contrário, essa prioridade normativa é tola e é necessário priorizar o controle cidadão do governo democrático, ou seja, é relevante dar primazia à justiça política (PETTIT, 2012, p. 25).

Pettit afirma que existe um argumento poderoso para dar uma certa prioridade à legitimidade democrática, qual seja: o argumento de que a própria atividade de propor um ideal ou teoria da justiça social pressupõe que deve haver um procedimento politicamente justo, objetivo e adequadamente democrático na sociedade. Além disso, Pettit ressalta que esse argumento se baseia em três suposições que os teóricos da justiça social contemporânea tendem a aceitar, a saber: 1 ) um processo de tomada de decisão politicamente justo deve ser estabelecido; 2 ) esse processo deve exigir uma forma de aprovação democrática; e 3) esse processo deve introduzir uma forma de controle democrático (PETTIT, 2015, p. 12).

Em relação à primeira suposição, Pettit assevera que as circunstâncias políticas acima mencionadas nos permitem pensar que as sociedades contemporâneas, para as quais as atuais teorias normativas rivais fazem recomendações diferentes, devem estabelecer um processo político de tomada de decisão para identificar, selecionar e implementar os padrões regulatórios que considerem adequados. Em particular, deve ser estabelecido um processo político que não se incline a favor de nenhuma das teorias normativas que fazem parte desse debate e que trate todos os cidadãos como iguais (PETTIT, 2015, p. 14).

Quanto à segunda suposição, Pettit adverte que esse primeiro requisito não permite estabelecer uma prioridade direta da justiça política sobre a justiça social, dado que, assim como existem diferenças entre as teorias da justiça social, também existem diferenças entre as teorias de justiça política Portanto, "as teorias elaboradas da justiça política têm o mesmo status normativo provisório que as teorias da justiça social" 
(PETTIT, 2015, p. 16). No entanto, essa primeira observação não prejudica a prioridade temporal e normativa da justiça política sobre a social, pois "a divergência entre teorias elaboradas da justiça política é consistente com a crença de que existe um processo mais básico e justo de tomada de decisão política que deve ser usado para acomodar as diferenças entre elas" (PETTIT, 2015, p. 16). Essa segunda observação, implicaria que os padrões das teorias da justiça social devem ser analisados de acordo com um processo político avaliativo que satisfaça a exigência de aprovação do cidadão democrático (PETTIT, 2015, p. 17).

Em relação à terceira suposição, Pettit ressalta que a prioridade temporal e normativa da justiça política sobre a justiça social não apenas parte da necessidade de um procedimento de deliberação e decisão, mas também exige que seja democrático. Contudo, esse procedimento pode ter defeitos, apresentar falhas na origem, desenvolvimento ou levar a resultados indesejados. Portanto, é necessário acrescentar a exigência de que o processo democrático permita que os cidadãos realizem o controle democrático "dando às pessoas uma voz igual no exercício do controle sobre o andamento desse processo" (PETTIT, 2015, p. 28).

\section{Objeções republicanas ao modelo democrático crítico de Honneth}

Partindo da análise comparativa realizada entre a concepção democrática crítica de Honneth e o republicano cívico de Pettit, explicaremos quatro objeções relativas à primeira, usando argumentos da segunda.

Primeiro, a teoria democrática crítica de Honneth assume como ferramenta metodológica a reconstrução normativa como um mecanismo para identificar e avaliar as práticas e instituições sociais em função dos padrões normativos de justiça imanentes a elas que formam uma eticidade democrática específica orientada por uma teleologia normativa moderna (HONNETH, 2014, p. 23). Na direção oposta, apontamos que o republicanismo de Pettit passa a criticar práticas e instituições sociais sem tentar justificar uma eticidade democrática específica, mas questiona os valores geralmente aceitos em cada sociedade, ainda que sejam parte da uma teleologia normativa moderna, se não promovem a liberdade como não-dominação (PETTIT, 2014, p. 1- 20). Assim, o método de reconstrução normativa empregado por Honneth estaria sujeito a duas objeções. Por um lado, ao elevar a padrões normativos generais aqueles valores situados que são amplamente aceitos em uma prática ou instituição social concreta, ainda que conexas a certa teleologia normativa moderna, desconhece a possibilidade de que exista uma fonte externa de avaliação normativa que 
não seja consistente com esses valores o com essa teleologia (CAMPELLO, 2013 , p. 189). ${ }^{5}$ Por outro lado, Honneth não cumpre sua própria proposta metodológica, uma vez que, na exposição efetiva de seu corpus teórico, não obtém três modelos de liberdade individual da forma indutiva, com base em um estudo detalhado das diversas maneiras por meio das quais o valor da liberdade individual é imanente a certas sociedades específicas. Em lugar disso, analisa de forma dedutiva modelos ideais, abstratos e analíticos da liberdade individuai que funcionam como concepções normativas independentes de práticas sociais situadas. Com isso, Honneth propõe um modelo ideal da liberdade individual rival ao oferecido por outros autores, e de certa maneira aplica esse modelo como padrão normativo independente aos fenômenos empíricos específicos de sociedades realmente existentes (CAMPELLO, 2013, p. 197).

Segundo, Honneth, em $O$ direito da liberdade, define positivamente a justiça como reconhecimento mútuo. Com isso, desaparece em demasia a dimensão de conflito presente na ideia de uma luta por reconhecimento. 0 ideal regulatório democrático deliberativo de Honneth implica entender a justiça social como pré-condição para a reciprocidade democrática entre os sujeitos políticos. No entanto, em um mundo complexo, glocal e plural como o atual, os processos políticos de deliberação e decisão não partem da existência de uma ordem social justa já existente. Pelo contrário, a situação atual exige processos democráticos deliberativos e decisórios que pressupõem desigualdade, injustiça e ilegitimidade, de modo que, tendo um horizonte normativo de não-dominação, sejam projetados cursos de ação política não ideais, compatíveis com a existência de discordâncias políticas profundas, inclusive sobre valores com justiça política e social (WALDRON, 2005, p. 1-10). ${ }^{6}$

Terceiro, a reconstrução analítica de Honneth, dos três modelos de liberdade individual, desconsidera teorias democráticas contemporâneas valiosas e respeitadas. Por um lado, o modelo negativo de liberdade individual parece desmoronar completamente na perspectiva libertária de autores como J. Locke, T. Hobbes ou R. Nozick, e não menciona outros liberalismos, como o liberalismo igualitário de J. Rawls, W. Galston ou J. Cohen (KYMLICKA, 2002). Por outro lado, Honneth conecta o modelo reflexivo da liberdade individual ao modelo republicano aristotélico, que geralmente é catalogado como republicanismo clássico, abrangente ou antigo, com base em uma concepção positiva de liberdade política. Dessa maneira, Honneth deixa de fora o republicanismo contemporâneo, político ou cívico, que se baseia em uma definição negativa do valor da liberdade política entendida como não-dominação (SILVA, 2011; 2015). Nesse entendimento, Honneth define o modelo reflexivo como intrassubjetivo, 
enfatizando a perspectiva interna do sujeito individual, sem considerar a perspectiva intersubjetiva que valoriza o aspecto externo simbólico e material. Quanto a isso, deve-se notar que o republicanismo, em sua versão cívica, não considera a face institucional e social como uma externalidade, mas inclui as noções de justiça social e Estado de direito constitucional como pressupostos da liberdade política entendida como não-dominação (PETTIT, 2012; 2014). Ademais, o modelo social de Honneth não considera várias teorias políticas críticas contemporâneas que consideram o social como um componente imanente da definição de liberdade política e defendem uma concepção deliberativa de democracia não sustentada em pressupostos hegelianos (DRYZEK, 2000).

Quarto, o modelo honnethiano está em contradição, já que, na primeira parte de seu trabalho, prioriza temporal e normativamente a ideia de ordem social justa sobre a de legitimidade democrática, enquanto na última parte de seu trabalho, ele aponta a predominância inversa, Por um lado, em contradição com a prioridade temporal da justiça social, afirma que a legitimidade democrática teria prioridade temporal sobre a justiça social por duas razões: i) somente os órgãos do Estado de Direito têm poder legítimo "em virtude das quais as modificações alcançadas pela sociedade em diferentes esferas de ação podem ser transformadas em atos sancionados e, portanto, em garantias legais" e ii) "somente a esfera da construção da vontade democrática é estabelecida, de acordo com seu princípio de liberdade, como lugar da auto-tematização reflexiva" (HONNETH, 2014, p. 441). Por outro lado, contrariando a prioridade normativa da justiça social, Honneth ressalta que "somente na esfera político-democrática o trabalho conjunto dos sujeitos é pensado como uma troca recíproca de argumentos" enquanto nas esferas relacionadas à justiça social "o trabalho cooperativo é estabelecido [...] como um complemento mútuo de implementações ou capacidades práticas de ação, e só pode ser aperfeiçoado de forma secundária por mecanismos reflexivos" (HONNETH, 2014, p. 441).

\section{Conclusão}

No presente trabalho, após explicar nosso objetivo geral e objetivos específicos, reconstruímos os pressupostos conceituais e normativos do modelo democrático crítico de Honneth; na sequência, apresentamos as bases do modelo republicano cívico de Pettit; para então, fazermos quatro objeções ao modelo de Honneth. Na presente seção explicaremos quatro vantagens comparativas atribuíveis ao modelo de Pettit sobre o de Honneth. 
Primeiro, o método de equilíbrio reflexivo empregado por Pettit mostra vantagens consideráveis sobre o da reconstrução normativa adotada por Honneth, identificando melhor as situações de dominação, assim como evitando o domínio de alguns grupos políticos sobre outros, sustentado em estândares normativos imanentes a certas práticas sociais concretas que respeitam uma controvertida teleologia normativa modernista.

Segundo, em comparação com a noção de reconhecimento mútuo adotada por Honneth, a definição de liberdade como não-dominação feita por Pettit tem uma maior capacidade explicativa em face das deficiências atualmente existentes na justiça, bem como uma maior capacidade transformadora, promovendo cursos de ação normativos não ideais que eliminam ou mitigam a referida opressão.

Terceiro, a classificação de Pettit sobre várias concepções do valor da liberdade política se baseia na bibliografia mais recente e precisa sobre filosofia política, evitando o uso de uma classificação sui generis como a de Honneth, que está aquém inclusive dos modelos teóricos existentes na bibliografia específica.

Quarto, há bons argumentos para defender, juntamente com P. Pettit, a prioridade do valor da justiça política sobre o da justiça social, dadas as condições normativas não ideais indicadas pelas circunstâncias da política. Isso evita impor o critério ideal de super-exigência de uma ordem social justa, desenvolvida por Honneth, que lhe dá prioridade temporal e normativa - ainda que caindo em contradições - sobre o processo democrático deliberativo. 


\section{Notas}

1 Títulos de graduação: Advogado (UNC), Professor Universitário (UCC). Pósgraduação: Doutor em Direito e CS. SC. (UNC), Mestrado em Direito e Argumentação Legal (UNC), Bolsista de Pós-Doutorado CONICET-IEHSOLP (20172019), Bolsista de Pós-Doutorado CONICET-UdG (2019-2021). Trabalho docente: Professor de História Constitucional (UNLPam) e Professor de Direito Constitucional (UNLPam). Local de trabalho: Faculdade de Direito da Universitat de Girona.

${ }^{2}$ Cabe advertir que todas as traduções de fragmentos do texto usadas neste artigo são do autor.

30 conceito de reconhecimento mútuo adotado por Honneth está inscrito em um modelo ético crítico que não seja o igualitário liberal. Por um lado, indica que as lutas sociais não podem ser descritas ou avaliadas seguindo o padrão das lutas de interesses. Por outro lado, ele afirma que certas teorias liberais igualitárias negligenciam as circunstâncias normativas não ideais em que certos sujeitos buscam seu reconhecimento, apontando que isso denota uma distância prejudicial entre filosofia e sociologia política (HONNETH, 2009, p. 48-49, 56-59).

4 No entanto, independentemente do caráter individual assumido por seu modelo social de liberdade política, Honneth adverte que, diante da atual crise do Estado democrático de direito, seria desejável "o agrupamento do poder político de entidades, movimentos sociais e associações para, em um esforço coordenado, pressionar o legislador parlamentar com grande intensidade para a adoção de medidas para redirecionar o mercado capitalista" (HONNETH, 2014, p. 435).

${ }^{5}$ Honneth parece assumir uma perspectiva avaliativa restringida, segundo a qual o que é considerado moralmente justo e legítimo depende de estândares imanentes a uma instituição ou prática social específica. Consideramos que isso é problemático, pois impediria avaliar negativamente aquelas situações de dominação estruturais que impõem um grupo de pessoas sobre outro sempre que sejam justificadas historicamente com base em um valor comumente aceito por uma instituição ou prática social específica. Em definitiva, Honneth parece não admitir que existem estândares normativos extrínsecos a práticas e instituições sociais que permitem a transformação e abertura de elas (AGUIAR SIMIM, 2015, p. 661).

6 F. Abril afirma que Honneth em $O$ direito da liberdade liquefaria parte do potencial explicativo e transformador de sua própria teoria ética crítica, já que: i) ele não usa as noções de dominação bilateral e consenso social implícito, o que permitiria relatar o acordo tácito existente entre o dominante e o dominado, observando que indivíduos e grupos estão ativamente envolvidos em processos conflitantes de negociação que dão alguma legitimidade às práticas atuais de dominação social; e ii) não define a ideia de reconhecimento mútuo como uma experiência conflituosa, mas como uma experiência cooperativa (ABRIL, 2016, p. 6-9). 


\section{Referências bibliográficas}

ABRIL, F. El problema de la dominación en El derecho de la libertad de Axel Honneth. Revista Pilquen. Sección Ciencias Sociales, Viedma, v. 19, n. 1, p. 1-12, 2016.

AGUIAR SIMIM, T. A justiça das instituições sociais. Uma crítica da reconstrução normativa de $\mathrm{O}$ direito da Liberdade de Axel Honneth. Civitas. Revista de Ciências Sociais, Porto Alegre, v. 15, n. 4, p. 648-663, 2015.

CAMPELLO, F. Do reconhecimento à liberdade social: sobre O direito da Liberdade de Axel Honneth. Cadernos de Ética e Filosofia Política, São Paolo, v. 2, n. 23, p. 185-199, 2013.

DRYZEK, J. Deliberative Democracy and Beyond. Oxford: Oxford U.P., 2000.

HONNETH, A. La lucha por el reconocimiento debe ser considerada un fenómeno claramente diferenciado de la naturaleza moral, así como una acción social. Barcelona: Katz, p. 45-85, 2009, Entrevista concedida a Daniel Gamper Sachse.

HONNETH, A. Reconocimiento y menosprecio. Sobre la fundamentación normativa de una teoría social. Barcelona: Katz, 2010.

HONNETH, A. El derecho de la libertad. Esbozo de una eticidad democrática. Buenos Aires: Katz, 2014.

KYMLICKA, W. Contemporary Political Philosophy. An introduction. 2 ed. Oxford, Oxford U. P., 2002.

PETTIT, P. On the People's Terms: A Republican Theory and Model of Democracy. Cambridge: Cambridge U. P., 2012.

PETTIT, P. Just freedom. A moral compass for a complex world. Norton: Nueva York, 2014.

PETTIT, P. Justice: Social and Political., In: SOBEL, D., VALLENTYNE, P., e WALL, S., (Eds.), Oxford Studies in Political Philosophy. Oxford: Oxford U. P., 2015. v. 1. p. 9-35.

SILVA, R. Republicanismo neo-romano e democracia contestatória. Revista da Sociologia Política, Curitiba, v. 19, n. 39, p. 35-51, 2011.

SILVA, R. Non-domination and Political Institutions: The Contested Concept of Republican Democracy. Brazilian Political Science Review, São Paolo, v. 9, n. 1, p. 3-38, 2015. 
WALDRON, J. Derechos y desacuerdos. Barcelona: Marcial Pons, 2005.

Received/Recebido: 24/06/20 Approved/Aprovado: 28/09/20 